\title{
Prevalence of Primitive Reflexes and Parkinsonian Signs in Dementia
}

\author{
K. A. Links, D. Merims, M. A. Binns, M. Freedman, T. W. Chow
}

\begin{abstract}
Objective: Primitive reflexes and parkinsonian signs are used by clinicians to differentiate among dementias. We reviewed our clinical sample to determine whether primitive reflexes were more prevalent in frontally-based dementias and whether parkinsonian signs were more common in dementia with Lewy bodies (DLB) than in other types of dementia. Design: We retrospectively reviewed charts from 204 patients with dementia who presented for consultation at Baycrest's Ross Memory Clinic between April, 2003, to December, 2007. Results: A greater proportion of subjects with DLB and dementia of the Alzheimer type with cardiovascular disease had primitive reflexes than subjects with frontotemporal dementia (FTD). Primitive reflexes were not positively predictive of FTD or vascular dementia $(\mathrm{VaD})$. Dementia with Lewy bodies subjects were more likely to have parkinsonian signs than the other dementias, and bradykinesia and rigidity were positively predictive of FTD. The palmomental reflex was the most common primitive reflex in the sample, and cogwheeling was the most common parkinsonian sign. There was no significant difference between early- and late-stage groups in presence of primitive reflexes or parkinsonian signs. Conclusions: Primitive reflexes appear not to be clinically discriminative of frontally-based dementias such as FTD and VaD.
\end{abstract}

RÉSUMÉ: Prévalence des réflexes primitifs et des signes parkinsoniens dans la démence. Objectif : Les réflexes primitifs et les signes parkinsoniens sont utilisés par les cliniciens pour faire la distinction entre les démences. Nous avons révisé nos observations cliniques pour déterminer si la prévalence des réflexes primitifs était plus élevée dans les démences frontales et si les signes parkinsoniens étaient plus fréquents dans la démence à corps de Lewy (DCL) par rapport aux patients atteints de d'autres types de démence. Plan de l'étude : Nous avons révisé rétrospectivement les dossiers de 204 patients atteints de démence qui ont consulté au Baycrest Hospital Ross Memory Clinic entre avril 2003 et décembre 2007. Résultats : Une proportion plus élevée de sujets atteints de DCL et de démence de type Alzheimer accompagnée de maladie cardiovasculaire avaient des réflexes primitifs que les patients atteints de démence frontotemporale (DFT). Les réflexes primitifs n'étaient pas des facteurs de prédiction positifs de la DFT ou de la démence vasculaire (DVA). Les sujets atteints de DCL étaient plus susceptibles d'avoir des signes parkinsoniens que les patients atteints d'autres démences et la bradycinésie et la rigidité étaient des facteurs de prédiction positifs de la DFT. Le réflexe palmo-mentonnier était le réflexe primitif le plus fréquent et la roue dentée était le signe parkinsonien le plus fréquent. Il n’y avait pas de différence significative entre les groupes en phase précoce et en phase tardive de la maladie quant à la présence des réflexes primitifs ou des signes parkinsoniens. Conclusions : Au point de vue clinique, les réflexes primitifs ne semblent pas être discriminants dans les démences frontales telles la DFT et la DVA.

Can. J. Neurol. Sci. 2010; 37: 601-607

Primitive reflexes are a group of innate motor behaviours present in infancy that presumably evolved to facilitate survival of the infant. ${ }^{1}$ Reflexes, such as snout, palmomental, grasp, and glabellar are present from birth and can be associated with feeding and attaching to mother, but are lost as the frontal lobes mature. ${ }^{2}$ In cases of neurological disorder affecting the frontal lobes, these primitive reflexes may reappear.

Given that frontotemporal dementias (FTD) selectively target the frontal and temporal lobes, the re-emergence of primitive reflexes in the patient seems not only plausible but is also considered a supportive diagnostic criterion. ${ }^{3}$ Primitive reflexes are often reported in patients with FTD, as well as those with stroke, tumors, or trauma to the frontal lobes. ${ }^{4}$ As such, the neurological examination of these patients often includes assessment for primitive reflexes.

Frontotemporal dementia is not the only cause for reemergence of primitive reflexes. A large-scale prospective study performed by the Canadian Study of Health and Aging confirmed that primitive reflexes are more likely to be present in more severely demented subjects than among those earlier in the course of illness or without cognitive impairment, and, accordingly, insufficient sensitivity for diagnostic utility, ${ }^{5}$ but this study did not include subjects with FTD. In addition, the prevalence of primitive reflexes increases with age for cognitively intact men and women; primitive reflexes appear commonly after age $66 .{ }^{6}$ Duration of illness and age therefore should be considered in analyses studying subjects with dementia but have not been addressed.

Parkinsonism is a neurological syndrome characterized by bradykinesia, resting tremor, postural instability, rigidity and parkinsonian gait. Combinations of these signs are also seen in

From the Dalla Lana School of Public Health (MAB), Department of Medicine, Division of Neurology (MF, TWC), Department of Psychiatry, Division of Geriatric Psychiatry (TWC), University Health Network-Mt. Sinai Hospital, Division of Neurology (MF), University of Toronto; Baycrest Rotman Research Institute (KAL, DM, MAB, MF, TWC); Baycrest Division of Neurology (DM, MF, TWC), Toronto, Ontario, Canada.

Received January 28, 2010. Final Revisions Submitted March 15, 2010 Correspondence to: Tiffany Chow, Baycrest, Rotman Research Institute, 3560 Bathurst Street, 8th Floor Brain Health Complex, Toronto, Ontario, M6A 2E1, Canada. 
patients with dementia with Lewy Bodies (DLB), ${ }^{7}$ in the "Parkinson-plus" syndromes (Progressive Supranuclear Palsy, ${ }^{8}$ Multisystems Atrophy, ${ }^{9}$ ) and in patients with advancing FTD and Alzheimer's disease (AD). ${ }^{10-17}$ If such a patient presents for medical attention late in the course of illness, it may be difficult to rule out DLB as an etiology for the dementia. ${ }^{18}$ One study reports the prevalence of parkinsonian signs, specifically akinesia, at $84 \%$ in FTD $(n=31),{ }^{12}$ which raises the question of how helpful parkinsonian signs at the initial examination may be in settling a differential diagnosis for dementia.

Baycrest's Ross Memory Clinic has followed patients with dementia with systematic documentation of the initial neurological evaluation for the past seven years. The purpose of this study was to inform clinicians of how positively or negatively predictive the presence or absence of primitive reflexes and parkinsonian signs were for the differential diagnosis of dementia.

We hypothesized that because dementia of different etiologies affects frontal lobes and basal ganglia at different points in the course of illness, the greatest prevalence of primitive reflexes was to be found in subjects with FTD of all etiologies, including behavioural variant FTD (bvFTD), semantic dementia (SD), progressive non-fluent aphasia (PNFA), corticobasal degeneration (CBD) and progressive supranuclear palsy (PSP), or those with significant cerebrovascular disease, as in vascular dementia (VaD), at the time of presentation to clinic. As per the McKeith diagnostic criteria for DLB,${ }^{7}$ we expected a greater prevalence of parkinsonian signs in subjects with DLB than in subjects with FTD, except those with CBD or PSP.

Furthermore, we expected to see greater incidence of primitive reflexes and parkinsonian signs in subjects with longer durations of illness (beyond four years post-onset) than in those in earlier stages of illness, regardless of etiology.

Taking advantage of a unique and sizeable clinical database, this study is among the first to inform specialists on the role of specific neurological examination findings in differential diagnosis of dementia.

\section{Study Design And Methods}

Subjects were Baycrest outpatients seen in consultation in the Ross Memory Clinic. Initial visits to this clinic entail a

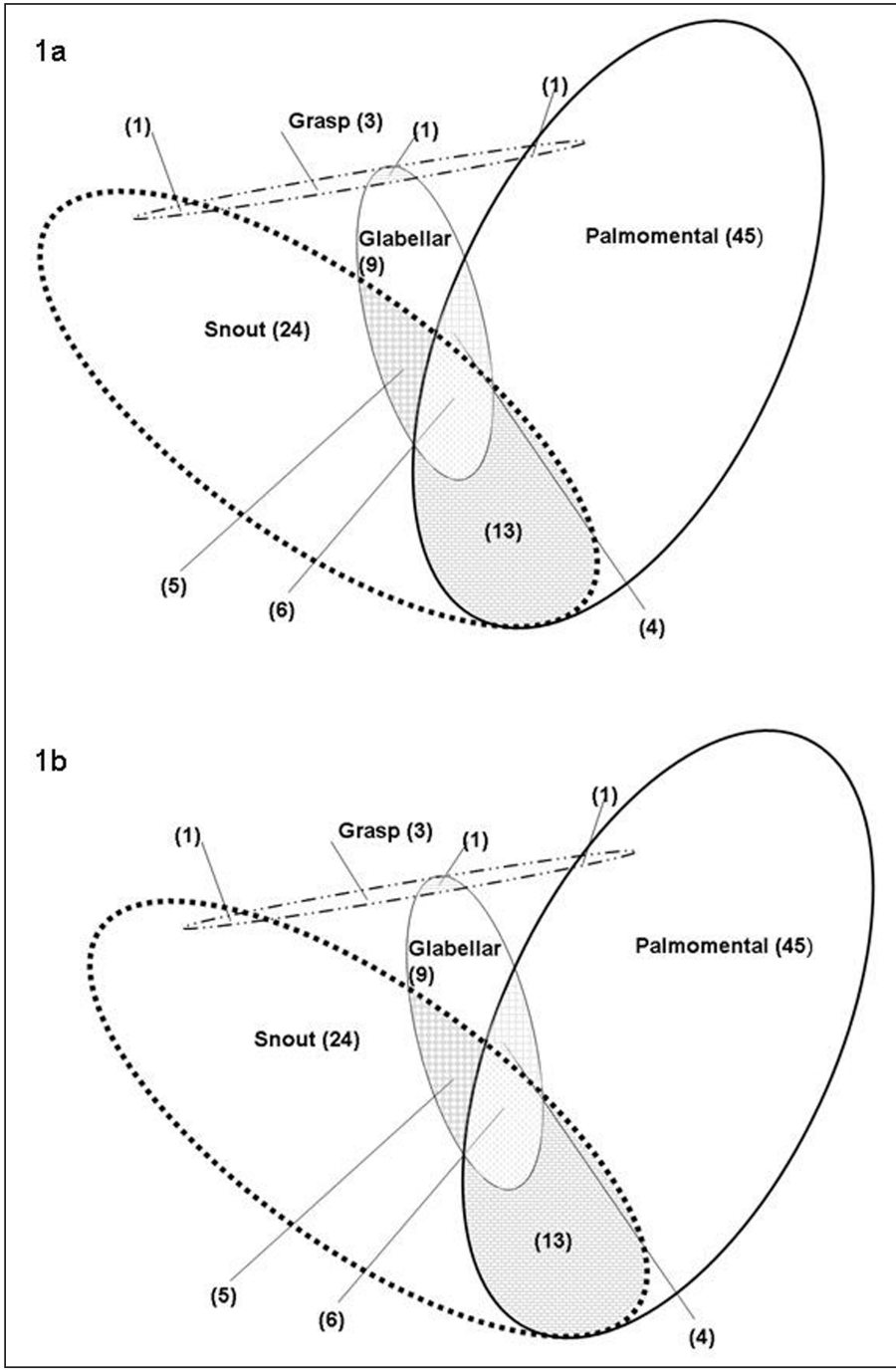

Figure: a) Modified Venn representation of prevalence of primitive reflexes. Each ovoid object represents the portion of subjects with a given primitive reflex. The overlap of objects represents the proportion of subjects with more than one primitive reflex present at initial examination. One subject with snout, palmomental, and grasp reflexes is not shown. b) Modified Venn representation of prevalence of parkinsonian signs. Each ovoid object represents the portion of subjects with a given parkinsonian sign. The overlap of objects represents the proportion of subjects with more than one parkinsonian sign present at initial examination. One subject with rigidity, resting tremor, and bradykinesia, one subject with cogwheeling, parkinsonian gait, and bradykinesia, and one subject with cogwheeling, rigidity, bradykinesia, and parkinsonian gait are not shown. Shading of ovoid objects is to highlight areas of overlap. 
standardized evaluation using a history and physical form that prompts informants and patients with a set template of questions about dementia symptoms and prompts the clincians to carry out all aspects of the elemental neurological examination, which includes the primitive reflexes and the parkinsonian signs used for this study. Examinations were either performed by or supervised by MF and TWC between April 1,2003, to December 31,2007 . Charts for review were identified retrospectively by billing records for Ontario Health Insurance Plan diagnosis code = 290 (Dementia) and service fee code A185 (Consultation). Inclusion criteria included meeting the clinical diagnostic criteria for dementia and initial history and physical forms available either in hard copy chart form or on the Citywide Registry System. This study was approved by the Baycrest Research Ethics Board.
Charts for 225 patients were reviewed (see Table 1 for characterization). Twenty-one subjects whose final diagnosis was not one of dementia (i.e., subjects who were deemed to have mild cognitive impairment, $\mathrm{n}=5$; or no cognitive impairment, $\mathrm{n}=16$ ), were excluded from the analysis. Twenty-one further subjects with $\mathrm{AD}$ and co-morbid Parkinson's disease $(n=2)$, dementia ${ }^{19}$ without an etiology specified $(n=15)$, or dementia due to multiple etiologies $(n=4)$ were excluded from the group analysis but included in the calculations of prevalence among dementias. The remaining sample of 183 subjects allowed comparisons among five common dementia etiologies: AD per the NINCDS-ADRDA Work Group criteria, ${ }^{20} \mathrm{VaD}$ per NINDSAIREN International Workshop criteria, ${ }^{21}$ DLB per criteria by McKeith et al., ${ }^{7}$ Alzheimer's Disease with co-morbid cerebrovascular disease (AD+CVD) per NINDS-AIREN International

Table 1: Characterization of the sample

\begin{tabular}{|c|c|c|c|c|c|c|}
\hline & \multirow[b]{2}{*}{$\begin{array}{c}\text { AD } \\
(n=106)\end{array}$} & \multicolumn{2}{|c|}{ FTD } & \multirow[b]{2}{*}{$\begin{array}{c}\mathrm{AD}+\mathrm{CVD} \\
(\mathrm{n}=19)\end{array}$} & \multirow[b]{2}{*}{$\begin{array}{c}\text { DLB } \\
(\mathrm{n}=17)\end{array}$} & \multirow[b]{2}{*}{$\begin{array}{l}\mathrm{VaD} \\
(\mathrm{n}=10)\end{array}$} \\
\hline & & $\begin{array}{c}\text { a) bvFTD, SD } \\
\text { \& PNFA } \\
(\mathrm{n}=26)\end{array}$ & $\begin{array}{l}\text { b) CBD } \\
\text { and PSP } \\
(\mathrm{n}=5)\end{array}$ & & & \\
\hline $\begin{array}{l}\text { Prevalence of Dementia Diagnosis in This Sample } \\
\mathrm{n}=204 \text { includes Other Dementia group }\end{array}$ & $51.96 \%$ & $12.75 \%$ & $2.45 \%$ & $9.31 \%$ & $8.33 \%$ & $4.90 \%$ \\
\hline Mean Age (SD) & $75.6 \pm 11.3$ & $63.8 \pm 10.0 *$ & $66.6 \pm 13.3$ & $81.9 \pm 6.0$ & $77.4 \pm 10.4$ & $73.1 \pm 10.02$ \\
\hline Sex (n, \% women) & $52,49.06 \%$ & $15,57.69 \%$ & $3,60.00$ & $16,84.21 \% * *$ & $8,47.06 \%$ & $3,30.00 \%$ \\
\hline Handedness (n, \% Right) & $100,94.34 \%$ & $25,96.15 \%$ & $4,80.00 \%$ & $17,89.47 \%$ & $15,88.24 \%$ & $9,90.00 \%$ \\
\hline Mean Duration of Illness (years) (SD) & $3.4 \pm 2.5$ & $3.5 \pm 2.3$ & $2.5 \pm 1.2$ & $3.9 \pm 2.2$ & $3.2 \pm 1.9$ & $5.7 \pm 3.3$ \\
\hline Mean MMSE (SD) & $21.0 \pm 6.8$ & $22.5 \pm 2.5$ & $17.4 \pm 5.0$ & $19.4 \pm 7.5$ & $18.4 \pm 7.7$ & $20.9 \pm 8.9$ \\
\hline Mean BNA-SF (maximum score $=114)(\mathrm{SD})$ & $61.8 \pm 23.5$ & $58.7 \pm 18.9$ & $53.5 \pm 12.4$ & $54.6 \pm 16.1$ & $55.8 \pm 17.6$ & $54.7 \pm 24.2$ \\
\hline Intact Basic ADLs (n, Column \%) & $71,66.98 \%{ }^{* * *}$ & $13,50.00 \%$ & $1,20.00 \%$ & $7,36.84 \%$ & $6,35.29 \%$ & $3,30.00 \%$ \\
\hline Intact Instrumental ADLs (n, Column \%) & $19,17.92 \%$ & $5,19.23 \%$ & $0,0.00 \%$ & $1,5.26 \%$ & $1,5.88 \%$ & $0,0.00 \%$ \\
\hline \multicolumn{7}{|l|}{ Psychiatric History } \\
\hline Psychosis/ Schizophrenia (n, Column \%) & $2,1.89 \%$ & $0,0.00 \%$ & $0,0.00 \%$ & $0,0.00 \%$ & $1,5.88 \%$ & $1,10.00 \%$ \\
\hline Depression Currently (n, Column \%) & $14,13.21 \%$ & $9,34.62 \%{ }^{\dagger}$ & $1,20.00 \%$ & $2,10.53 \%$ & $2,11.76 \%$ & $2,20.00 \%$ \\
\hline Past Depression (n, Column \%) & $11,10.38 \%$ & $4,15.38 \%$ & $1,20.00 \%$ & $2,10.53 \%$ & $2,11.76 \%$ & $2,10.00 \%$ \\
\hline Anxiety (n, Column \%) & $45,42.45 \%$ & $14,53.85 \%$ & $2,40.00 \%$ & $4,21.05 \%$ & $8,47.06 \%$ & $3,30.00 \%$ \\
\hline Head Injury (n, Column \%) & $25,23.58 \%$ & $9,34.62 \%$ & $2,40.00 \%$ & $6,31.58 \%$ & $4,23.53 \%$ & $5,50.00 \%$ \\
\hline \multicolumn{7}{|l|}{ Stroke Risk Factors ${ }^{\dagger \dagger}$} \\
\hline $\begin{array}{l}\text { Presence of One or More Stroke Risk Factors } \\
(\mathrm{n}, \text { Column \%) }\end{array}$ & $77,72.64 \%$ & $14,53.85 \%$ & $4,80.00 \%$ & $18,94.74 \%$ & $15,88.24 \%$ & $10,100.00 \%$ \\
\hline \multicolumn{7}{|l|}{ Medication Usage } \\
\hline Cholinesterase Inhibitors (n, Column \%) & $40,37.74 \%$ & $10,38.46 \%$ & $2,40.00 \%$ & $11,57.89 \%$ & $6,35.29 \%$ & $1,10.00 \%$ \\
\hline Dopaminergics (n, Column \%) & $30,28.30 \%$ & $2,7.69 \%$ & $1,20.00 \%$ & $2,10.53 \%$ & $3,17.65 \%$ & $0,0.00 \%$ \\
\hline Serotonergic Agents (n, Column \%) & $28,26.42 \%$ & $8,30.77 \%$ & $1,20.00 \%$ & $5,26.32 \%$ & $1,5.88 \%$ & $5,50.00 \%$ \\
\hline Tricyclic Antidepressants (n, Column \%) & $2,1.89 \%$ & $1,3.85 \%$ & $0,0.00 \%$ & $1,5.26 \%$ & $0,0.00 \%$ & $0,0.00 \%$ \\
\hline Antipsychotics (n, Column \%) & $14,13.21 \%$ & $3,11.54 \%$ & $0,0.00 \%$ & $3,15.79 \%$ & $3,17.65 \%$ & $0,0.00 \%$ \\
\hline Benzodiazepines (n, Column \%) & $10,9.43 \%$ & $0,0.00 \%$ & $0,0.00 \%$ & $1,5.26 \%$ & $1,5.88 \%$ & $0,0.00 \%$ \\
\hline Pro-parkinsonian Drugs (n, Column \%) & $12,11.32 \%$ & $3,11.54 \%$ & $0,0.00 \%$ & $3,15.79 \%$ & $1,5.88 \%$ & $0,0.00 \%$ \\
\hline Anti-parkinsonian Drugs (n, Column \%) & $0,0.00 \%$ & $0,0.00 \%$ & $0,0.00 \%$ & $2,10.53 \%$ & $7,41.18 \%$ & $0,0.00 \%$ \\
\hline
\end{tabular}

* FTDa $<$ AD, p < 0.001; FTDa $<$ DLB, p < 0.01; FTDa $<$ AD + CVD, p < 0.0001; ** AD + CVD > AD, p < $0.005 ;$ AD + CVD $>$ DLB,$p<0.01 ;$ $\mathrm{AD}+\mathrm{CVD}>\mathrm{VaD}, \mathrm{p}<0.01 ; \mathrm{AD}+\mathrm{CVD}>\mathrm{FTDa}, \mathrm{p}<0.05 ; * * * \mathrm{AD}>\mathrm{DLB}, \mathrm{p}<0.01 ; \mathrm{AD}>\mathrm{VaD}, \mathrm{p}<0.09 ; \mathrm{AD}>\mathrm{AD}+\mathrm{CVD}, \mathrm{p}<0.05 ; \mathrm{AD}>\mathrm{FTDb}$, $\mathrm{p}<0.05 ; \dagger$ FTDa $>$ AD, $\mathrm{p}<0.01 ; \dagger \dagger$ Stroke risk factors include Hypertension, Diabetes, Heart Disease, Hyperlipidemia, Peripheral Vascular Disease; $\mathrm{AD}=$ Alzheimer's Disease; FTDa= Behavioural Variant FTD, Semantic Dementia and Progressive Non-Fluent Aphasia; FTDb= Corticobasal Degeneration and Progressive Supranuclear Palsy; AD + CVD= Dementia of the Alzheimer's Type with Cerebrovascular Disease; DLB= Dementia with Lewy Bodies; VaD= Vascular Dementia; $\mathrm{SD}=$ Standard deviation; BNA-SF=Behavioural Neurology Assessment short form; ADL=activities of daily living. 
Table 2: Primitive Reflexes. n for cells of this table vary due to subjects' inability to comply with full neurological examination

\begin{tabular}{|c|c|c|c|c|c|c|}
\hline & \multicolumn{2}{|c|}{ FTD } & \multirow{2}{*}{$\begin{array}{l}\mathrm{VaD} \\
(\mathrm{n}=10)\end{array}$} & \multirow{2}{*}{$\begin{array}{c}\mathrm{AD}+\mathrm{CVD} \\
(\mathrm{n}=19)\end{array}$} & \multirow{2}{*}{$\begin{array}{c}\text { AD } \\
(n=100)\end{array}$} & \multirow{2}{*}{$\begin{array}{c}\text { DLB } \\
(\mathrm{n}=16)\end{array}$} \\
\hline & $\begin{array}{c}\text { bvFTD, SD \& } \\
\text { PNFA } \\
(\mathrm{n}=24)\end{array}$ & $\begin{array}{l}\text { CBD and } \\
\text { PSP } \\
(\mathrm{n}=5) \\
\end{array}$ & & & & \\
\hline Glabellar* (n, Column \%) & $1,4.17 \%$ & $1,20.00 \%$ & $3,30.00 \%$ & $7,36.84 \%$ & $\begin{array}{l}10,9.90 \% \\
(\mathrm{n}=101)\end{array}$ & $\begin{array}{l}6,35.29 \% \\
(\mathrm{n}=17)\end{array}$ \\
\hline Snout ** (n, Column \%) & $4,16.67 \%$ & $3,60.00 \%$ & $3,30.00 \%$ & $8,42.11 \%$ & $19,19.00 \%$ & $5,31.25 \%$ \\
\hline Unilateral Palmomental (n, Column \%) & $1,4.17 \%$ & $1,20.00 \%$ & $1,10.00 \%$ & $2,10.53 \%$ & $4,4.00 \%$ & $0,0.00 \%$ \\
\hline Palmomental- bilateral (n, Column \%) & $4,16.67 \%$ & $3,60.00 \%$ & $4,40.00 \%$ & $7,36.84 \%$ & $29,29.00 \%$ & $6,37.50 \%$ \\
\hline Unilateral Grasp (n, Column \%) & $0,0.00 \%$ & $0,0.00 \%$ & $0,0.00 \%$ & $0,0.00 \%$ & $0,0.00 \%$ & $0,0.00 \%$ \\
\hline Grasp- bilateral (n, Column \%) & $1,4.17 \%$ & $0,0.00 \%$ & $0,0.00 \%$ & $2,10.53 \%$ & $2,2.00 \%$ & $1,6.25 \%$ \\
\hline $\begin{array}{l}\text { Mean Number of Primitive Reflexes Per } \\
\text { Subject (SD) }\end{array}$ & $0.44 \pm 0.71$ & $0.80 \pm 1.30$ & $1.0 \pm 0.82$ & $1.33 \pm 1.4$ & $0.61 \pm 0.73$ & $1.00 \pm 0.87$ \\
\hline $\begin{array}{l}\text { Presence Of One or More Primitive } \\
\text { Reflexes*** (n, Column \%) }\end{array}$ & $7,29.17 \%$ & $2,40.00 \%$ & $7,70.00 \%$ & $15,78.95 \%$ & $\begin{array}{l}50,49.50 \% \\
(\mathrm{n}=101)\end{array}$ & $12,75.00 \%$ \\
\hline
\end{tabular}

*DLB $>$ AD, p < 0.005; DLB > FTDa , p <0.01; VaD > FTDa, p <0.05; AD + CVD > FTDa, p $<0.01 ; * *$ FTDb $>$ FTDa, $\mathrm{p}<0.05 ; * * *$ DLB vs. bvFTD, SD \& PNFA, $\mathrm{p}<0.01 ;$ AD + CVD vs. bvFTD, SD \& PNFA, p $<0.001$

Workshop criteria,,${ }^{1-21}$ and FTD. ${ }^{3}$ The FTD group analysis was further subdivided into two groups: a) those with bvFTD, SD and PNFA, and b) those with CBD and PSP, per criteria by Litvan et al. ${ }^{8}$

Data were collected from the clinic history and physical form items covering presence of primitive reflexes (glabellar, snout, palmomental and grasp) and parkinsonian signs (cogwheeling, rigidity, parkinsonian gait, resting tremor and bradykinesia). Each of these variables was examined independently, but analyses were also conducted to characterize the overall prevalence of primitive reflexes or parkinsonian signs within each diagnostic group, as well as the average number of signs present across diagnostic groups.

The data set included demographics and standardized mental status test scores, i.e., the Mini-Mental Status Examination $(\mathrm{MMSE})^{22}$ and the Behavioural Neurology Assessment- Short Form (BNA-SF) ${ }^{23}$. For the assessment of activities of daily living (ADLs), the Memory Clinic's history and physical form includes a brief checklist of basic and instrumental ADLs. Patients are recorded as being independent, requiring assistance, or dependent for each of the items on the list (e.g., basic ADL = bathing or feeding self; instrumental ADL = handling finances or keeping appointments). This study ranked subjects as independent in all ADLs, requiring assistance for only instrumental ADLs, or impaired in all ADLs.

We recorded use of psychotropic medications, in the event that antipsychotic drugs or selective serotonergic reuptake inhibitors would be associated with presence of parkinsonian signs due to extrapyramidal side effects. Many more subjects with cerebrovascular disease than other dementia groups were taking lipid-reducing statin drugs, which warranted exploration as well. To further test our hypothesis about cerebrovascular disease in frontal lobes leading to disinhibition of primitive reflexes, we collected data on stroke risk factors (hypertension, diabetes, heart disease, hyperlipidemia, peripheral vascular disease, history of transient ischemic attack/stroke) and potential signs of stroke found on exam (decreased motor strength, asymmetric deep tendon reflexes, unilateral Babinski reflexes, unilateral or bilateral decreased amplitude on fast finger movements or rapid alternating movements). These same variables might support the alternate diagnosis of vascular parkinsonism, if present in non-DLB groups.

Duration of illness was noted for stratification to early- versus late-stage dementia groups. Early-stage dementia was defined as presenting to the Ross Memory Clinic less than four years postonset.

\section{ANALYSIS}

Tests were reported as significant for $\mathrm{p}$ values below the Type I error level of 0.05. One-way ANOVA and chi-square tests were used to compare the six groups on demographic variables. Tukey's test was used for post-hoc comparison.

We used chi-squared analysis to compare the dementia groups for relative prevalence of primitive reflexes and separately for relative prevalence of parkinsonian signs. Dementia severity at times limited compliance with a full neurological examination, leading to unequal numbers of subjects from whom each primitive reflex or parkinsonian sign contributed to the analysis. We have denoted the number of diagnosed subjects along with the number of subjects for whom data was available in each cell of Table 2 .

Furthermore, we calculated unadjusted positive predictive values using our own observed prevalence rates. These were calculated as follows:

$$
\frac{a}{a+b}
$$

where ' $a$ ' is the number of individuals in the diagnostic group of interest presenting with a particular sign and ' $b$ ' is the number of individuals presenting with the sign in the remaining diagnostic groups. This then yields the proportion of subjects in a diagnostic 
Table 3: Positive predictive value of primitive reflexes and parkinsonian signs

\begin{tabular}{|c|c|c|c|c|}
\hline $\begin{array}{c}\text { Sign } \\
\text { Parkinsonism } \\
\rightarrow \text { Prim Reflex }\end{array}$ & Diagnosis & $\begin{array}{c}\text { Diagnostic } \\
\text { Prevalence } \\
\text { Rate }\end{array}$ & $\begin{array}{l}\text { Predictive } \\
\text { Value of } \\
\text { Sign }\end{array}$ & $\begin{array}{l}\text { Index of } \\
\text { Impact }\end{array}$ \\
\hline Bradykinesia & DLB & $8.33 \%$ & $40.00 \%$ & $31.67 \%$ \\
\hline Bradykinesia & FTDa & $12.75 \%$ & $40.00 \%$ & $27.25 \%$ \\
\hline Parkinsonian Gait & DLB & $8.33 \%$ & $34.62 \%$ & $26.28 \%$ \\
\hline Grasp & $\mathrm{AD}+\mathrm{CVD}$ & $9.31 \%$ & $25.00 \%$ & $15.69 \%$ \\
\hline Bradykinesia & $\mathrm{VaD}$ & $4.90 \%$ & $20.00 \%$ & $15.10 \%$ \\
\hline Resting Tremor & DLB & $8.33 \%$ & $22.22 \%$ & $13.89 \%$ \\
\hline Glabellar & $\mathrm{AD}+\mathrm{CVD}$ & $9.31 \%$ & $21.88 \%$ & $12.56 \%$ \\
\hline Cogwheeling & DLB & $8.33 \%$ & $20.00 \%$ & $11.67 \%$ \\
\hline Glabellar & DLB & $8.33 \%$ & $18.75 \%$ & $10.42 \%$ \\
\hline Snout & $\mathrm{AD}+\mathrm{CVD}$ & $9.31 \%$ & $16.67 \%$ & $7.35 \%$ \\
\hline Rigidity & FTDb & $2.45 \%$ & $9.52 \%$ & $7.07 \%$ \\
\hline Parkinsonian Gait & $\mathrm{AD}+\mathrm{CVD}$ & $9.31 \%$ & $15.38 \%$ & $6.07 \%$ \\
\hline
\end{tabular}

The first column lists signs of parkinsonism on the left side and primitive reflexes on the right. Index of Impact is the difference between the predictive value of a sign, and the diagnostic prevalence rate.

group with a particular sign, present relative to the number of subjects with the same sign in the total study sample.

Logistic regression was used to determine whether a relationship existed between the psychotropic medications or statins and presence of either primitive reflexes or parkinsonian signs. Logistic regression was also conducted for effects of either early or late dementia stage, with dementia diagnostic group, age, and gender as covariates.

Independent samples t-tests were conducted to determine whether there was a difference in mean duration of illness and cognitive test scores between those who presented with or without primitive reflexes or parkinsonian signs.

\section{RESULTS}

\section{Characterization of the Sample}

Table 1 lists demographic information, medication usage, and the prevalence rates for dementia groups within our sample. Consistent with the characteristic early onset of FTD, the FTDa group (bvFTD, SD and PNFA) was significantly younger than the subjects of the $\mathrm{AD}, \mathrm{AD}+\mathrm{CVD}$, and $\mathrm{DLB}$ groups. There were more women in the $\mathrm{AD}+\mathrm{CVD}$ group than in $\mathrm{AD}, \mathrm{DLB}, \mathrm{VaD}$ or FTDa groups. The AD group had a significantly greater proportion of subjects with intact basic ADLs than did the DLB, $\mathrm{VaD}, \mathrm{AD}+\mathrm{CVD}$ or FTDb (CBD and PSP groups). The FTDa group had a significantly greater number of subjects with comorbid depression than did AD.

Small vessel disease accounted for $40 \%$ of $\mathrm{VaD}$ cases $(\mathrm{n}=4)$. Fifty percent of the VaD cases $(n=5)$ had a combination of small vessel disease and cortically-based infarcts, and $10 \%(n=1)$ had a left frontal cortical infarct only. The majority of subjects with AD+CVD (14/19, 73.7\%) had small vessel disease consisting of lacunes and/or periventricular white matter disease. An additional $10 \%$ of subjects with AD+CVD (2/19) had a combination of small vessel disease and cortically-based infarcts. The remaining 3 of the 19 had cortical infarcts, 2 of which were based in the left frontal lobe.

\section{Primitive Reflexes}

The palmomental reflex was the most common primitive reflex overall, followed by the snout reflex (see Figure 1a). Snout was more common in FTDb (CBD and PSP) than in FTDa (bvFTD, SD and PNFA, see Table 2). None of the primitive reflexes increased the likelihood of either set of FTD diagnoses or VaD above our observed prevalences (see Table 3). Despite the substantial proportion of FTDa subjects $(29.17 \%)$ with at least one primitive reflex at presentation, significantly greater proportions of DLB and AD+CVD patients presented with primitive reflexes (see Table 2).

Primitive reflexes were also prevalent within the $\mathrm{VaD}$ group (70\%). Cerebrovascular disease comorbidity with $\mathrm{AD}$ seems to have added to the prevalence of primitive reflexes over $\mathrm{AD}$ alone. Grasp, glabellar and snout reflexes increased the likelihood of an $\mathrm{AD}+\mathrm{CVD}$ diagnosis over our observed prevalence of $9.1 \%$ (see Table 3). In addition, $\mathrm{AD}+\mathrm{CVD}$ had the greatest mean number of primitive reflexes present (see Table 2). Regardless of the associations between $\mathrm{AD}+\mathrm{CVD}$ and $\mathrm{VaD}$ with primitive reflexes, we found no association between number of stroke risk factors (regardless of diagnosis) and the presence of primitive reflexes. Potential signs of stroke were as rare in subjects with primitive reflexes as in those without.

Those who presented with one or more primitive reflexes at the initial consultation were significantly older than those who did not display frontal release signs $(\mathrm{t}=-3.075, \mathrm{df}=195, \mathrm{p}=$ 0.002). DLB, $A D$ and $A D+C V D$ groups were all significantly older than were those in the FTDa group. Differences in primitive reflexes between groups remained significant when age was added as a covariate.

There was no significant sex difference in the proportion of participants presenting with primitive reflexes. Subjects taking psychotropic medications did not have a statistically greater number of primitive reflexes than those who were not taking medications, and age and sex results did not change substantively when psychotropic medications were added to regression models.

\section{Parkinsonian signs}

Cogwheeling was the most frequently reported parkinsonian sign across all diagnostic groups (see Figure 1b), and cogwheeling was not specific to DLB but improved predictive ability. Subjects with DLB had mainly cogwheeling without rigidity (70.6\%). The proportion of DLB subjects presenting with one or more parkinsonian signs was greater than in $\mathrm{AD}$, $\mathrm{VaD}, \mathrm{AD}+\mathrm{CVD}$ or FTDa (see Table 4). The average number of parkinsonian signs present was also greater in DLB. All signs but rigidity were more common in DLB than in the other dementia diagnoses, but rigidity was significantly more common in subjects with FTDb (CBD or PSP) than in VaD or AD+CVD.

Bradykinesia was most positively predictive of DLB and increased the probability of FTDa or VaD diagnoses (see Table 3). All of the parkinsonian signs but rigidity increased the likelihood of a DLB diagnosis. 
Table 4: Parkinsonian signs. n for cells of this table may vary due to subjects' inability to comply with full neurological examination

\begin{tabular}{|c|c|c|c|c|c|c|}
\hline & \multirow{2}{*}{$\begin{array}{l}\text { DLB } \\
(\mathrm{n}=17)\end{array}$} & \multirow{2}{*}{$\begin{array}{c}\text { AD } \\
(n=106)\end{array}$} & \multirow{2}{*}{$\begin{array}{c}\mathrm{VaD} \\
(\mathrm{n}=10)\end{array}$} & \multirow{2}{*}{$\begin{array}{c}\mathrm{AD}+\mathrm{CVD} \\
(\mathrm{n}=19)\end{array}$} & \multicolumn{2}{|c|}{ FTD } \\
\hline & & & & & $\begin{array}{l}\text { a) bvFTD, } \\
\text { SD \& PNFA } \\
(\mathrm{n}=26)\end{array}$ & $\begin{array}{l}\text { b) CBD and } \\
\text { PSP } \\
(n=4)\end{array}$ \\
\hline Prior Diagnosis of Parkinson's Disease* (n, Column \%) & $4,23.53 \%$ & $0,0.00 \%$ & $0,0.00 \%$ & $0,0.00 \%$ & $1,3.85 \%$ & $\begin{array}{l}0,0.00 \% \\
(\mathrm{n}=5)\end{array}$ \\
\hline Cogwheeling** (n, Column \%) & $12,70.59 \%$ & $30,28.30 \%$ & $2,20.00 \%$ & $3,15.79 \%$ & $3,11.54 \%$ & $0,0.00 \%$ \\
\hline Rigidity*** (n, Column \%) & $2,11.76 \%$ & $1,0.94 \%$ & $2,20.00 \%$ & $3,15.79 \%$ & $3,11.54 \%$ & $2,50.00 \%$ \\
\hline Resting Tremor (n, Column \%) & $4,23.53 \%$ & $9,8.49 \%$ & $0,0.00 \%$ & $0,0.00 \%$ & $1,3.85 \%$ & $0,0.00 \%$ \\
\hline Bradykinesia $^{\dagger}(\mathrm{n}$, Column \%) & $2,11.76 \%$ & $0,0.00 \%$ & $1,10.00 \%$ & $0,0.00 \%$ & $2,7.69 \%$ & $0,0.00 \%$ \\
\hline Parkinsonian Gait ${ }^{\dagger \dagger}(\mathrm{n}$, Column \%) & $9,52.94 \%$ & $\begin{array}{l}4,3.85 \% \\
(\mathrm{n}=104)\end{array}$ & $1,10.00 \%$ & $4,21.05 \%$ & $2,8.00 \%$ & $0,0.00 \%$ \\
\hline Mean Number of Parkinsonian Signs per Subject + SD & $1.76+1.3$ & $0.44+.62$ & $0.40 \pm 0.70$ & $0.53 \pm 0.84$ & $0.26 \pm 0.45$ & $0.50 \pm 0.58$ \\
\hline $\begin{array}{l}\text { Presence Of One or More Parkinsonian Signs } \\
(\mathrm{n}, \text { Column \%) }\end{array}$ & $13,76.47 \%$ & $41,38.68 \%$ & $3,30.00 \%$ & $7,36.84 \%$ & $7,26.92 \%$ & $2,50.00 \%$ \\
\hline
\end{tabular}

$* \mathrm{DLB}>\mathrm{AD}, \mathrm{p}<0.00000005 ; \mathrm{DLB}>\mathrm{VaD}, \mathrm{p}<0.01 ; \mathrm{DLB}>\mathrm{AD}+\mathrm{CVD}, \mathrm{p}<0.05 ; \mathrm{DLB}>\mathrm{FTDa}, \mathrm{p}<0.05 ; * * \mathrm{DLB}>\mathrm{AD}, \mathrm{p}<0.01 ; \mathrm{DLB}>\mathrm{AD}+\mathrm{CVD}$, $\mathrm{p}<0.001$, DLB $>$ FTDa, $\mathrm{p}<0.0001 ;$ DLB $>$ FTDb, p $<0.01 ; * * *$ DLB $>$ AD, p $<0.01 ;$ DLB $>$. AD + CVD, p <0.05; FTDb vs $>$ FTDa, p <0.05; FTDb $>$ $\mathrm{VaD}, \mathrm{p}<0.01 ;$ FTDb vs. DAT + CVD, $<<0.01 ; \dagger \mathrm{DLB}$ vs. AD, $\mathrm{p}<0.0005 ; \dagger+\mathrm{DLB}>\mathrm{AD}, \mathrm{p}<0.000000001 ; \mathrm{DLB}>\mathrm{VaD}, \mathrm{p}<0.05 ; \mathrm{DLB}>\mathrm{AD}+\mathrm{CVD}$, $\mathrm{p}<0.05$, DLB $>$ FTDa, $\mathrm{p}<0.001$; DLB vs. FTDb, $\mathrm{p}<0.05 ; \dagger+\uparrow \mathrm{DLB}>\mathrm{AD}, \mathrm{p}<0.00000005 ; \mathrm{DLB}>\mathrm{VaD}, \mathrm{p}<0.0005 ; \mathrm{DLB}>\mathrm{AD}+\mathrm{CVD}, \mathrm{p}<0.0001 ; \mathrm{DLB}$ $>$ FTDa, $<<0.0000001 ;$ \#LB $>$ AD, $p<0.005 ;$ DLB $>$ VaD, $p<0.01 ;$ DLB $>$ AD + CVD, p $<0.01 ;$ DLB $>$ FTDa, $<<0.001$

We found no association between number of stroke risk factors (regardless of diagnostic group) or potential signs of stroke and the presence of parkinsonian signs. Subjects with parkinsonian signs were older on average than were those who did not present with parkinsonian signs $(t=-3.23$, df $=203, p=$ 0.001). A logistic regression model of the presence of Parkinsonian signs that included both psychotropic medications and statins as possible confounds did not substantially change the results.

\section{Timing during course of illness}

Early and late stage groups did not differ significantly in the proportion of primitive reflexes or parkinsonian signs. Instead, there was an interaction between the stage of illness and dementia type that affected the prevalence of parkinsonian signs. Parkinsonian signs were more prevalent in the FTDa early stage of illness group $\left(\chi^{2}=5.07, \mathrm{df}=1, \mathrm{p}=0.024\right)$ than in FTDa presenting during the later stages of their illness. The average number of parkinsonian signs was also higher in the early stage FTDa group $(\mathrm{t}=2.41, \mathrm{df}=24, \mathrm{p}=0.024)$.

Other measures indicated that severity of illness correlated with the presence of both primitive reflexes and parkinsonian signs. A higher proportion of subjects with parkinsonian signs were impaired in basic ADLs than those not exhibiting parkinsonian signs $\left(\chi^{2}=5.85, \mathrm{df}=1, \mathrm{p}=0.016\right)$. Mini-Mental Status Examination scores of subjects with one or more primitive reflexes present were lower on average (mean $=19.69)$ than those who did not display them $($ mean $=22.53 ; \mathrm{t}=2.86, \mathrm{df}=184$, $\mathrm{p}=0.005$ ). Subjects' BNA-SF scores were more impaired when one or more primitive reflexes were present at time of initial consult $($ mean $=56.3)$ than were those without primitive reflexes (mean $=64.67 ; \mathrm{t}=2.57, \mathrm{df}=174, \mathrm{p}=0.011)$. Subjects with at least one primitive reflex had lower scores on average on the executive function section of the BNA-SF than did those without frontal release signs $(t=3.11, \mathrm{df}=167, \mathrm{p}=0.002)$. Specifically, the executive functioning score on the BNA-SF was impaired in the DLB group with frontal release signs $(\mathrm{t}=2.26, \mathrm{df}=13, \mathrm{p}=$ $0.041)$. Scores from other cognitive domains tested by the BNASF (memory, visuoconstruction, language) did not yield significant results.

Behavioural Neurology Assessment- Short Form scores were also significantly lower for those subjects with any dementia who exhibited parkinsonian signs (mean $=56.8$ ) as compared with those who did not show any signs $($ mean $=64.6 ; \mathrm{t}=2.38, \mathrm{df}$ $=196, \mathrm{p}=0.018)$.

\section{Discussion}

Contrary to our study hypotheses, primitive reflexes were not more common in subjects with any of the FTD etiologies or VaD at the time of initial consultation. Instead, primitive reflexes were present in $70.6 \%$ of DLB cases and $77.8 \%$ of AD+CVD cases, and this appears to support Van Boxtel et al's claim that prevalence of primitive reflexes increases with age,${ }^{6}$ as opposed to dementia etiology. Primitive reflexes also seemed more associated with functional and cognitive status indicators (basic ADLs, MMSE and BNA-SF) than with dementia etiology.

The lack of association of primitive reflexes with FTD in our results may not be generalizable. Our prevalence of at least one primitive reflex in the FTDa group combining bvFTD, SD and PNFA (29.17\%) was lower than the approximately $37 \%$ prevalence in bvFTD reported by Piguet. ${ }^{24}$

As expected from the diagnostic criteria, parkinsonian signs were more prevalent and more positively predictive of DLB than of other dementia etiologies. While much more prevalent in 
DLB, parkinsonian signs were not uncommon in other diagnoses. As others have suggested, caution may therefore be warranted in ruling out $\mathrm{AD}$, the much more common diagnosis, based on the presence of these signs. ${ }^{25,26}$ Cogwheeling was the most commonly reported parkinsonian sign overall, but we were unable with the data available to distinguish which cases had cogwheeling due to postural tremor. This finding should, therefore, be interpreted conservatively. As opposed to primitive reflexes, bradykinesia was positively predictive of FTDa and $\mathrm{VaD}$.

This study gave a systemized description of 204 cases of dementia and revealed that primitive reflexes may be more indicative of advanced age, severity of illness, or diagnosis of $\mathrm{DLB}$ or $\mathrm{AD}+\mathrm{CVD}$. The presence of parkinsonian signs may be indicative of behavioural variant FTD, PNFA, semantic dementia, and $\mathrm{VaD}$ in addition to DLB. It is important to note that some of our diagnostic groups are quite small (particularly the FTDb group, $n=5$ ), raising caution against over-interpreting our results.

\section{Conclusions}

Although we looked for the associations of primitive reflexes and parkinsonism with types of dementia in several ways, there was no redundance in the use of specific variables, obviating the need to correct $\mathrm{p}$ values for multiple comparisons. A national multi-centre study to update prevalences of dementia and to review signs at presentation of autopsy-confirmed cases might strengthen these conclusions. In addition, given what is known about inheritance of FTDP-17 mutations and the incidence of parkinsonism in family members of probands with FTD or the presence of parkinsonism as a feature of FTD,${ }^{27}$ future studies should include data on family history.

\section{ACKNOWLEDGEMENTS}

The authors thank Ms. Taryn Moss of CAMH and Mr. Bernard Kadosh of Baycrest for their help with data collection. This work was funded by the Ontario Mental Health Foundation (MF), the Saul A. Silverman Family Foundation, as part of the Canada International Scientific Exchange Program (CISEPO) project (MF); Canadian Institutes of Health Research 53267 (MF); NIA grant F32 AG022802 (TWC); the University of Toronto Dean's Fund for New Faculty (\#457494 TWC); an endowment to the Sam and Ida Ross Memory Clinic (TWC, $\mathrm{MF}$ ); and a gift from the Moir Family (KL).

\section{REFERENCES}

1. Cummings J, Miller B. Conceptual and clinical aspects of the frontal lobes. In: Miller B, Cummings J, editors. The human frontal lobes. 2 ed. New York: The Guilford Press; 2007. p. 12-21.

2. Absher JR, Cummings JL. Neurobehavioural examination of frontal lobe functions. Aphasiology. 1995;9(2):181-92.

3. Neary D, Snowden JS, Gustafson L, et al. Frontotemporal lobar degeneration: a consensus on clinical diagnostic criteria. Neurology. 1998;51(6):1546-54.

4. Mumenthaler M. Neurologic differential diagnosis. 2 ed. New York: Thieme Medical Publishers, Inc; 1992.

5. Hogan DB, Ebly EM. Primitive reflexes and dementia: results from the Canadian Study of Health and Aging. Age Ageing. 1995;24(5):375-81.
6. van Boxtel MP, Bosma H, Jolles J, Vreeling FW. Prevalence of primitive reflexes and the relationship with cognitive change in healthy adults: a report from the Maastricht Aging Study. J Neurol. 2006;253(7):935-41.

7. McKeith IG, Dickson DW, Lowe J, et al. Diagnosis and management of dementia with Lewy bodies: third report of the DLB Consortium. Neurology. 2005;65(12):1863-72.

8. Litvan I, Agid Y, Calne D, et al. Clinical research criteria for the diagnosis of progressive supranuclear palsy (Steele-RichardsonOlszewski syndrome): report of the NINDS-SPSP International Workshop. Neurology. 1996;47:1-9.

9. Gilman S, Low P, Quinn N, et al. Consensus statement on the diagnosis of multiple system atrophy. Clin Auton Res. 1998;8(6): 359-62.

10. Kövari E. Neuropathological spectrum of frontal lobe dementias. Front Neurol Neurosci. 2009;24:149-59.

11. Claassen DO, Parisi JE, Giannini C, Boeve BF, Dickson DW, Josephs KA. Frontotemporal dementia mimicking dementia with Lewy bodies. Cogn Behav Neurol. 2008;21(3):157-63.

12. Diehl-Schmid J, Schulte-Overberg J, Hartmann J, Förstl H, Kurz A, Häussermann P. Extrapyramidal signs, primitive reflexes and incontinence in fronto-temporal dementia. Eur J Neurol. 2007;14 (8):860-4.

13. Mackenzie IR. The neuropathology and clinical phenotype of FTD with progranulin mutations. Acta Neuropathol. 2007;114(1): 49-54.

14. Leverenz JB, Yu CE, Montine TJ, et al. A novel progranulin mutation associated with variable clinical presentation and tau, TDP43 and alpha-synuclein pathology. Brain. 2007;130: 1360-74.

15. Le Ber I, van der Zee J, Hannequin D, et al. Progranulin null mutations in both sporadic and familial frontotemporal dementia. Hum Mutat. 2007;28(9):846-55.

16. Baker M, Mackenzie IR, Pickering-Brown SM, et al. Mutations in progranulin cause tau-negative frontotemporal dementia linked to chromosome 17. Nature. 2006;442(7105):916-9.

17. Hodges JR, Davies RR, Xuereb JH, et al. Clinicopathological correlates in frontotemporal dementia. Ann Neurol. 2004;56(3): 399-406.

18. Yoshita M, Taki J, Yamada M. A clinical role for [123I]MIBG myocardial scintigraphy in the distinction between dementia of the Alzheimer's-type and dementia with Lewy bodies. J Neurol Neurosurg Psychiatry. 2001;71:574-5.

19. American Psychiatric Association. Diagnostic and statistical manual of mental disorders (4th edition, text revision) (DSM-IVTR). Washington, DC: American Psychiatric Association, 2000.

20. McKhann G, Drachman D, Folstein M, et al. Clinical diagnosis of Alzheimer's disease: report of the NINCDS-ADRDA work group under the auspices of department of health and human services task force on Alzheimer's disease. Neurology. 1984;34: 939-44.

21. Román GC, Tatemichi TK, Erkinjuntti T, et al. Vascular dementia: diagnostic criteria for research studies: report of the NINDSAIREN International Workshop. Neurology. 1993;43:250.

22. Folstein MF, Folstein SE, McHugh PR. "Mini-Mental State": a practical method for grading the cognitive state of patients for the clinician. J Psychiatr Res. 1975;12:189-98.

23. Darvesh S, Leach L, Black SE, Kaplan E. The behavioural neurology assessment. Can J Neurol Sci. 2005;32:167-77.

24. Piguet O, Hornberger M, Shelley BP, Kipps CM, Hodges J. Sensitivity of current criteria for the diagnosis of behavioral variant frontotemporal dementia. Neurology. 2009;72:732-7.

25. Funkenstein HH, Albert MS, Cook NR, et al. Extrapyramidal signs and other neurologic findings in clinically diagnosed Alzheimer's disease: a community-based study. Arch Neurol. 1993;50(1):51-6.

26. Piguet O, Halliday GM, Creasey H, Broe GA, Kril JJ. Frontotemporal dementia and dementia with Lewy bodies in a case-control study of Alzheimer's disease. Int Psychogeriatr. 2009;21(4):688-95.

27. Boeve BF, Hutton M. Refining frontotemporal dementia with parkinsonism linked to chromosome 17 introducing FTDP-17 (MAPT) and FTDP-17 (PGRN). Arch Neurol. 2008;65(4):460-4. 